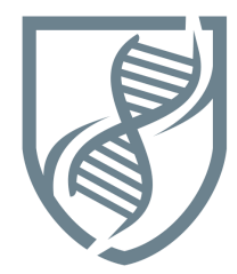

Journal of Bioscience and Applied Research

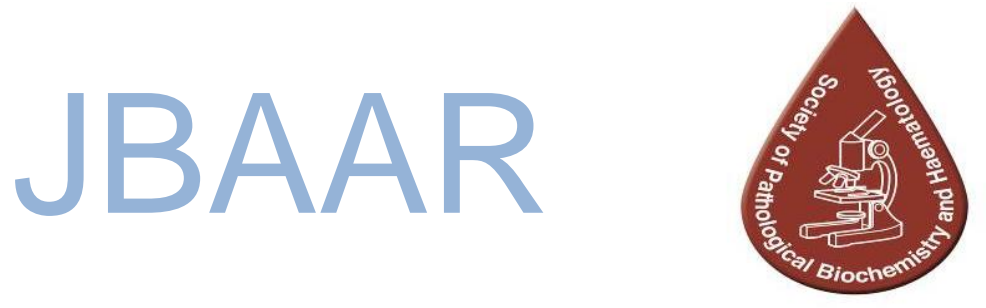

WWW.JBAAR.ORG

\title{
Review
}

\section{miRNA-122 from Laboratory biomarker to the treatment of $\mathrm{HCV}$}

\author{
Ahmed Abdelhalim Yameny \\ Society of Pathological Biochemistry and Hematology, Egypt \\ (Email: dr.ahmedyameny @yahoo.com) Phone: (002)01002112248
}

\begin{abstract}
Hepatitis C virus (HCV) is an important human pathogen that infects as many as 185 million persons worldwide, In the long-term, this can lead to advanced liver fibrosis, cirrhosis, and hepatocellular carcinoma HCC, there is currently no vaccine for hepatitis C. About $15-45 \%$ of infected persons spontaneously clear the virus within 6 months of infection without any treatment, miRNAs are endogenous short single-stranded noncoding RNAs and they are post-transcriptional negative regulators of gene expression, about18-22 nucleotides long, and play a crucial role in the regulation of gene expression. Now there are over 2500 mature potential human microRNAs recorded in miRBase (version 20, accessed January 2014), 84 miRNAs in serum and plasma of HCV-infected patients to identify miRNAs that correlated with different stages histologically assessed liver disease severity and during HCV infection, miRNA-122 is the most abundant in the liver,miRNA-122 is responsible' for liver homeostasis, several studies showed that miRNA-122 is required for $\mathrm{HCV}$ replication in infected cells, it can use as a serum biomarker over alanine leucine transaminase(ALT) in predicting the presence of chronic HCV infection, miR-122 also plays a crucial role in the regulation of cholesterol and fatty acid metabolism in the adult liver, and was identified as a regulator for systematic iron homeostasis, therapies that target it could present an effective approach for the development of new HCV antiviral drugs, Recently, the development of the anti-miR122 therapeutic miravirsen. Miravirsen (formerly SPC3649) is a 15-base oligonucleotide that is complementary to part of miR-122 and is the first miRNA-targeting agent administered to patients. Miravirsen has demonstrated in vitro antiviral activity against all HCV genotypes, Miravirsen interferes with the functions of miR-122 both in viral proliferation and in cholesterol homeostasis, miravirsen has demonstrated broad antiviral activity and a relatively high genetic barrier to resistance.
\end{abstract}

DOI: 10.21608/jbaar.2017.125861

Keywords: Hepatitis; Biomarker; HCV; miR-122; Liver disease; HCC; miravirsen; HBV, anti-miRNA 122

\section{HCV}

Hepatitis C virus (HCV) is an important human pathogen that infects as many as 185 million persons worldwide, suffer from chronic hepatitis C. Approximately $3 \%$ of the world population is infected with $\mathrm{HCV}$, and the severe consequences of virus infection make HCV one of the most pressing emergencies worldwide (World Health 
Organization, http://www.who.int/). In the long-term, this can lead to advanced liver fibrosis, cirrhosis, and hepatocellular carcinoma HCC. HCV is the most common indication for liver transplantation in developed countries ${ }^{(1)}$. Hepatitis $\mathrm{C}$ is a liver disease caused by the hepatitis $\mathrm{C}$ virus: the virus can cause both acute and chronic hepatitis, ranging in severity from a mild illness lasting a few weeks to a serious, lifelong illness, The hepatitis $\mathrm{C}$ virus is a bloodborne virus, there is currently no vaccine for hepatitis C, approximately 399 000 people die each year from hepatitis C, mostly from cirrhosis and hepatocellular carcinoma $^{(2)}$. Hepatitis $\mathrm{C}$ virus was first identified as a non- A, non-B hepatitis (3). About $15-45 \%$ of infected persons spontaneously clear the virus within 6 months of infection without any treatment, the remaining $60-80 \%$ of persons will develop chronic HCV infection, of those with chronic HCV infection, the risk of cirrhosis of the liver is between 15-30\% within 20 years ${ }^{(2)}$. Hepatitis $\mathrm{C}$ virus (HCV) is a hepatotropic, enveloped, single-stranded, and positive-sense RNA virus that belongs to the family Flaviviridae and genus hepacivirus. The viral genome contains $5^{\prime}$ and $3^{\prime}$ untranslated regions (UTR) that are important for viral replication and translation $^{(4)}$.

\section{miRNAs}

MicroRNAs (miRNAs) were discovered in 1993 during a developmental timing experiment in

the nematode Caenorhabditis elegans. miRNAs are endogenous short singlestranded noncoding RNAs and they are post-transcriptional negative regulators of gene expression, they selectively bond the complementary 3' UTR mRNAs and target for translational repression or cleavage ${ }^{(5)}$. These miRNAs account for only $1 \%$ of the human genome. miRNAs are highly conserved in nearly all organisms, about1822 nucleotides long, and play a crucial role in the regulation of gene expression ${ }^{(6,7)}$. In recent years miRNAs have become firmly established as key molecular components of the cell in both normal and pathogenic states $^{(8)}$. It was quickly recognized that micro- RNAs have a broad functional significance throughout the animal and plant kingdoms. Now there are over 2500 mature potential human microRNAs recorded in miRBase (version 20, accessed January 2014), a searchable database of published microRNAs and their annotation $^{(9)}$. Recent studies demonstrate that miRNAs are associated with various diseases, including cancer, viral infection, bacterial infection, and chronic diseases, because a single miRNA can regulate the expression of many cellular mRNAs, additionally, circulating miRNAs are also found in human serum and plasma, so can be used as candidate biomarkers for many diseases, also miRNAs increased or decreased with some diseases so can be used for the treatment of these diseases by synthetic miRNAs or using synthetic AntimiRNA according to its level with the disease. Which opens new hope for early diagnosis of many diseases and treat many acute and chronic diseases.

\section{Micro-RNAs in Hepatitis C}

Shrivastava et al. measured 84 miRNAs in serum and plasma of $\mathrm{HCV}$-infected patients to identify miRNAs that correlated with different stages histologically assessed liver disease severity and during $\mathrm{HCV}$ infection, which validated by real-time reverse-transcriptase polymerase chain reaction (PCR), they reported that serum miR-20a and miR-29a levels were significantly higher in $\mathrm{HCV}$ subjects with fibrosis ${ }^{(10)}$. (Fig. 1) 


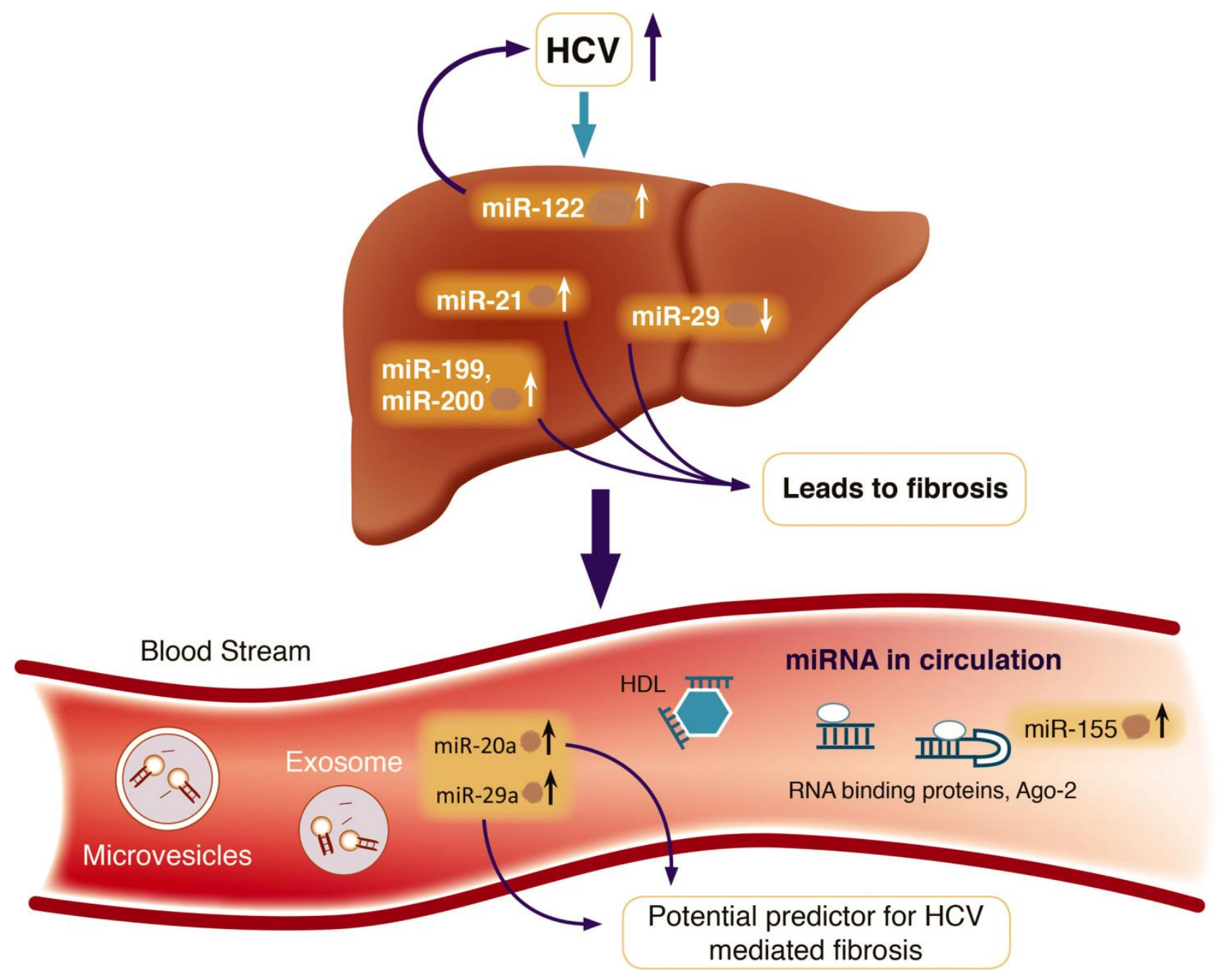

Fig. 1. Association of miRs with HCV infection and disease progression. Various intrahepatic and circulating miRNAs that are induced or repressed with $\mathrm{HCV}$ infection and associated with the progression of fibrosis are shown. (HEPATOLOGY 2013;58:863-871).

\section{MiRNA-122}

Recent studies have reported several miRNAs as key players in virus-host interactions, which regulating virus replication and pathogenesis during HCV infection (11). MiRNA-122 is responsible for liver homeostasis ${ }^{(12)}$. Several studies showed that miRNA-122 is required for $\mathrm{HCV}$ replication in infected cells ${ }^{(13,14)}$. It is positively modulated by direct interaction with viral RNA and stimulates its translation ${ }^{(15)}$. One miR-122 molecule binds to the $5^{\prime}$ UTR of HCV RNA with $3^{\prime}$ overhanging nucleotides, masking the $5^{\prime}$ terminal sequencing of $\mathrm{HCV}$ genome during translation, specific internal nucleotides, as well as $3 /$ terminal nucleotides in miRNA-122, were required for maintaining $\mathrm{HCV}$ RNA abundance ${ }^{(16)}$. Expression of miR-122 allows efficient HCV RNA replication and/or infectious virion production in a cell line ${ }^{(17)}$. The serum level of miR-122 and miR-21 strongly correlates with serum alanine leucine transaminase levels (ALT) and higher necroinflammatory activity in the liver in patients with $\mathrm{HCV}$ infection can using as a serum biomarker over ALT in predicting the presence of chronic HCV infection ${ }^{(18,19)}$. miR-122 is one of the most abundant miRNAs in the liver and has a liver-enriched expression accounting for about $70 \%$ in adult mice and $52 \%$ in humans of the whole hepatic miRNAs ${ }^{(20-22)}$.

Consequently, miR-122 plays a central role in liver development, differentiation, homeostasis, and functions (Fig. 2). The fact that the repression of miR-122 in primary $\mathrm{HCC}$ with poor prognosis was associated with suppression of the hepatic phenotype ${ }^{(23)}$. miR-122 also plays a crucial role in the regulation of cholesterol and fatty acid metabolism in the adult liver and was identified as a regulator for systematic iron homeostasis (Fig. 2). Indeed, antisense-mediated inhibition of 
hepatic miR-122 markedly lowered plasma cholesterol levels in both mice and non-human primates $^{(24-26)}$. Although the molecular mechanisms underlying the regulation of lipid homeostasis by miR-122 are still unclear, both
AMP-activated protein kinase (APK) and circadian

metabolic regulators of the peroxisome proliferator-activated receptor (PPAR) family were suggested to be putative effectors of miR122-mediated metabolic control ${ }^{(25,7}$ (Fig. 2).

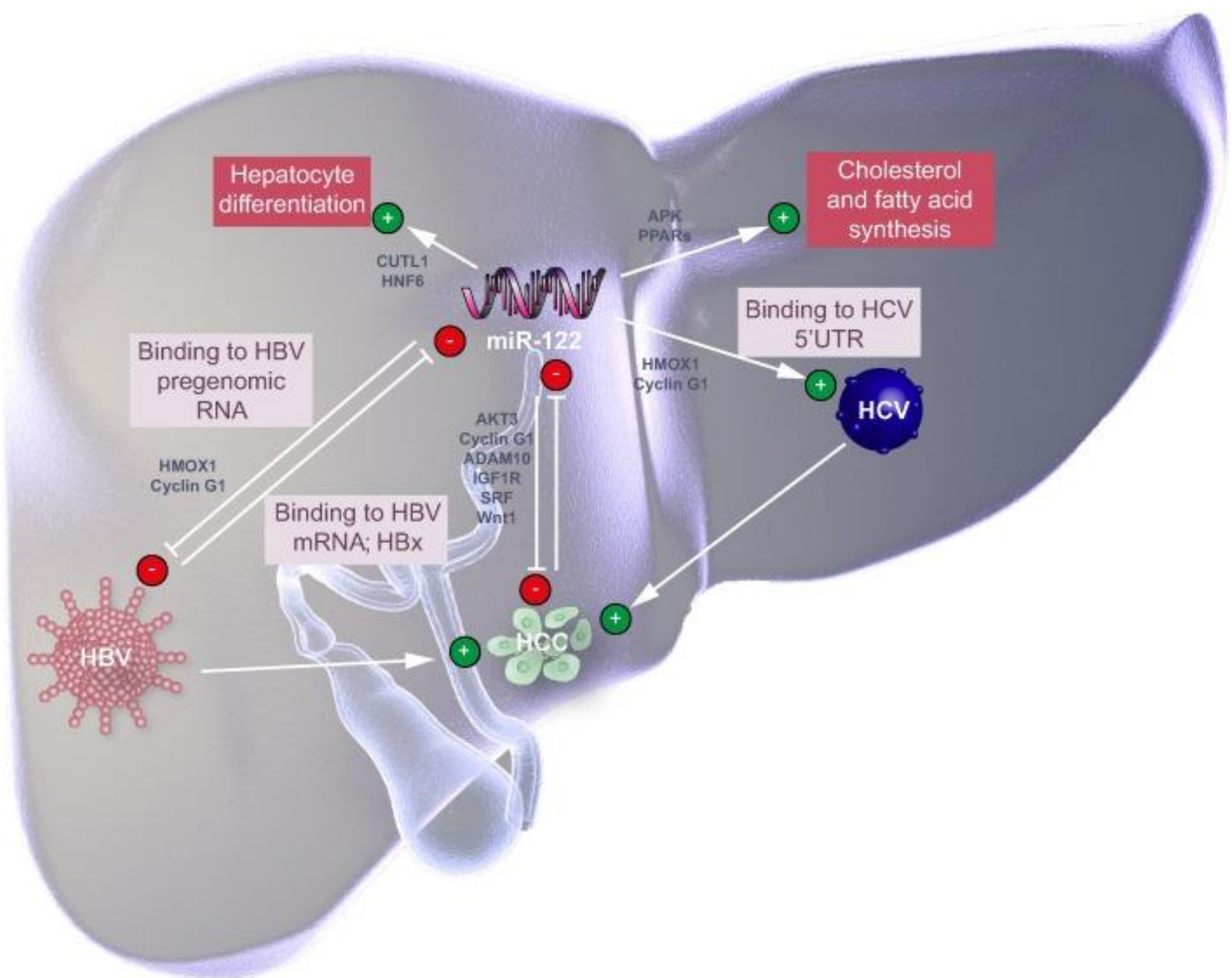

Fig. 2. miR-122 is a key regulator of liver physiology and disease biology. The scheme illustrates the different roles of miR-122 in liver development and metabolism (red boxes) as well as in viral hepatitis and liver disease. Activation (+) or inhibition (_) is indicated depending on the effect of miR122 on a specific process. While host miR-122 targets are depicted outside of boxes, miR-122 targets of viral origin are indicated within grey boxes.

\section{miR-122 as a therapeutic in HCV}

miR-122 is an essential host factor required for $\mathrm{HCV}$ replication, so therapies that target it could present an effective approach for the development of new HCV antiviral drugs. Synthetic therapeutic of miRNA-122 employing antisense oligonucleotide complementary to the $5^{\prime}$-end of miRNA-122, has been evaluated in $\mathrm{HCV}$ infected Chimpanzees $^{(28)}$. Resulted in a reduction of HCV viral load in the liver and blood of chronically infected Chimpanzees, with normalization of the interferon pathway ${ }^{(28)}$. by using a mouse model where tumors developed in the absence of inflammation, it has been demonstrated that miR-122 has an anti-tumor function that is independent of its role in preventing liver disease and inflammation ${ }^{(29)}$. miR-122 mimics represent an interesting strategy to prevent and treat HCC (Fig. 3). Recently, the development of the anti-miR122 therapeutic miravirsen. Miravirsen (formerly SPC 3649) is a 15-base oligonucleotide that is complementary to part of miR-122 and is the first miRNA-targeting agent administered to patients. 
Miravirsen has demonstrated in vitro antiviral activity against all HCV genotypes $^{(30)}$. In a clinical trial in treatment-naive patients with chronic $\mathrm{HCV}$ infection, miravirsen monotherapy was prolonged, and reversible pharmacodynamic responses (decreases in cholesterol levels) and demonstrated continuous and prolonged antiviral activity with no evidence of genetic resistance ${ }^{(31)}$. Miravirsen as HCV antiviral drug is the first miRNA-targeting antisense agent administered to patients $^{(31)}$. Miravirsen interferes with the functions of miR-122 both in viral proliferation and in cholesterol homeostasis ${ }^{(13)}$. The study by
Søren Ottosen et al (2015), In Vitro Antiviral Activity and Preclinical and Clinical Resistance Profile of Miravirsen, a Novel Anti-Hepatitis C Virus Therapeutic Targeting the Human Factor miR-122, showed that miravirsen has demonstrated broad antiviral activity and a relatively high genetic barrier to resistance. The identification of nucleotide changes associated with miravirsen resistance should help further elucidate the biology of miR-122 interactions with $\mathrm{HCV}^{(32)}$. (The clinical trial study has been registered at ClinicalTrials.gov under registration no. NCT01200420).
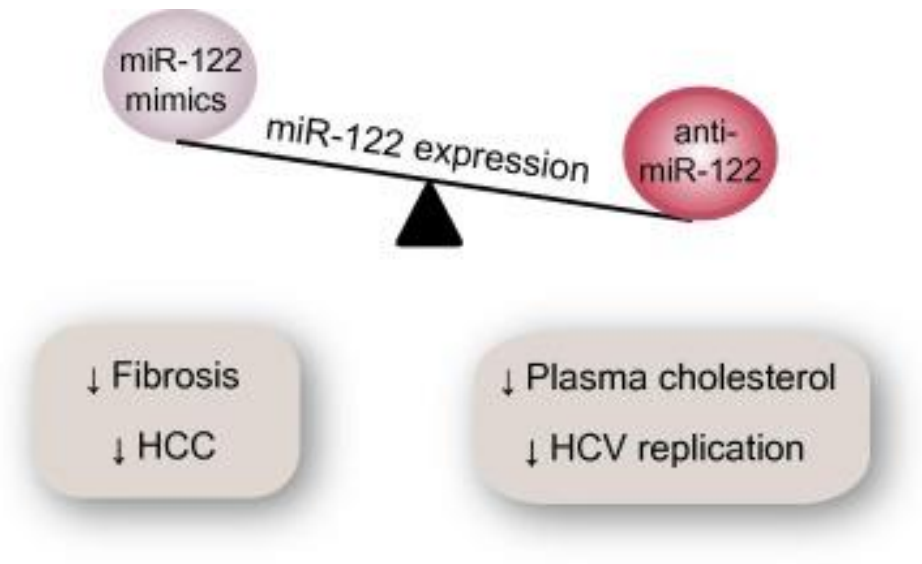

Fig. 3. Therapeutic effects of miR-122-modulating agents in liver disease Current state-of-the-art approaches in modulating miRNAs in vivo comprise restoration of miRNA expression, using synthetic miRNA mimics or viral vectors driving miRNA expression, as well as inhibition of miRNA expression via chemically modified anti-miR oligonucleotides ${ }^{(33)}$. While antisense-mediated inhibition of miR-122 (anti-miR-122) has been demonstrated of clinical interest to treat chronic HCV infection and to represent a potential therapeutic strategy against hypercholesterolemia, restoration of miR-122 (miR-122 mimics), was suggested as a therapeutic approach against liver fibrosis and HCC development

The discovery of small-molecule inhibitors of miRNA-122 function is a novel approach to inhibit HCV replication in liver cells, no adverse side effects of miRNA-122 inhibition have been reported in either chimpanzees or chronic HCV infected patients, it gives new hope to treat millions of people infected with different genotypes HCV in the world, without any complications caused by some other drugs for the treatment of $\mathrm{HCV}$ infection as hepatocellular carcinoma(HCC). Efficacy and safe treatment of HCV-infected patients will decrease the possibility of the development of fibrosis or cirrhosis which develops to HCC. miRNA-122 used as a serum biomarker for $\mathrm{HCV}$ infection and viral replication also for treatment follow-up, using anti-miRNA-122 can prevent virus replication decreasing viral load, and help the immune system of the infected person to overcome the $\mathrm{HCV}$ virus.

According to studies in animal models and human clinical trials miravirsen is effective and safe as a therapeutic in HCV without toxicity sometimes called genotherapy.

This technology of treatment of HCV virus can also be used for the treatment of other viral infection as HBV, HIV, Ebola virus and other dangerous viruses which still without treatment drug and open new hope for effective treatment of these viruses using the specific miRNA of each virus. 


\section{References}

1- D.L. ThomasGlobal control of hepatitis C: where challenge meets opportunity, Nat. Med., 19 (2013), pp. 850-858

2- WHO Report Hepatitis C fact sheets 2017.

3- Choo QL, Kuo G, Weiner AJ, Overby LR, Bradley DW, Houghton M. Isolation of cDNA clone derived from a blood-borne non-A, non-B viral hepatitis genome. Science. 1989;244-362.

4- Moradpour D, Penin F. Hepatitis C virus proteins: from structure to function. Curr Top Microbiol Immunol. 2013;369: $113 \mathrm{e} 142$.

5- Zeng Y, Yi R, Cullen BR (2003) MicroRNAs and small interfering RNAs can inhibit mRNA expression by similar mechanisms. Proc Natl Acad Sci U S A 100: 9779-9784.

6- Friedman RC, Farh KK, Burge CB, Bartel DP. Most mammalian mRNAs are conserved targets of microRNAs. Genome Res. 2009; 19:92-105.

7- Bartel DP. MicroRNAs: target recognition and regulatory functions. Cell. 2009;136:215-233.

8- Ebert, M.S., and Sharp, P.A.(2012) Roles for miRNAs in conferring robustness to biological processes. Cell 149, 515- 524

9- Griffiths-Jones, S. et al. (2008) miRBase: tools for microRNA genomics. Nucleic Acids Res. 36, D154-D158

10- Shrivastava S, Petrone J, Steele R, Lauer GM, Bisceglie AM, Ray RB.

Upregulation of circulating miR-20a is correlated with hepatitis $\mathrm{C}$ virusmediated liver disease progression. HEPATOLOGY 2013;58:863-871.

11- Li ZY, Xi Y, Zhu WN, Zeng C, Zhang ZQ, Guo ZC, Hao DL, Liu G, Feng L, Chen HZ, et al. Positive regulation of hepatic miR122 expression by HNF4 $\alpha \mathrm{J}$ Hepatol. 2011;55:602-611.

12- Tsai WC, Hsu SD, Hsu CS, Lai TC, Chen SJ, Shen $\mathrm{R}$, Huang $\mathrm{Y}$, Chen $\mathrm{HC}$, Lee $\mathrm{CH}$, Tsai $\mathrm{TF}$, et al. MicroRNA-122 plays a critical role in liver homeostasis and hepatocarcinogenesis. J Clin Invest.2012;122:2884-2897.

13- Jopling $C L$, Yi $M$, Lancaster $A M$, Lemon SM, Sarnow P. Modulation of hepatitis C virus RNA abundance by a liver-specific
MicroRNA. Science. 2005;309:15771581.

14- Jangra RK, Yi M, Lemon SM. Regulation of hepatitis $C$ virus translation and infectious virus production by the microRNA miR-122. J Virol. 2010;84:6615-6625.

15-Zhang C, Huys A, Thibault PA, Wilson JA. Requirements for human Dicer and TRBP in microRNA-122 regulation of $\mathrm{HCV}$ translation and RNA abundance. Virology. 2012;433:479-488.

16-. Machlin ES, Sarnow P, Sagan SM. Masking the $5^{\prime}$ terminal nucleotides of the hepatitis $C$ virus genome by an unconventional microRNA-target RNA complex. Proc Natl Acad Sci USA. 2011;108:3193-3198.

17- Narbus CM, Israelow B, Sourisseau $M$, Michta ML, Hopcraft SE, Zeiner GM, Evans MJ. HepG2 cells expressing microRNA miR-122 support the entire hepatitis C virus life cycle.J Virol. 2011;85:12087-12092.

18- Bihrer V, Friedrich-Rust $M$, Kronenberger B, Forestier N, Haupenthal J, Shi Y, Peveling-Oberhag J, Radeke HH, Sarrazin C, Herrmann E, et al. Serum miR-122 as a biomarker of necroinflammation in patients with chronic hepatitis C virus infection. Am Gastroenterol. 2011;106:1663-1669.

19-Cermelli S, Ruggieri A, Marrero JA, loannou GN, Beretta L. Circulating microRNAs in patients with chronic hepatitis $C$ and non-alcoholic fatty liver disease. PLoS One. 2011;6:e23937.

20-Lagos-Quintana M, Rauhut R, Yalcin A, Meyer J, Lendeckel W, Tuschl T. Identification of tissue-specific microRNAs from mouse. Curr Biol 2002;12: 735-739.

21-Girard M, Jacquemin E, Munnich A, Lyonnet S, Henrion-Caude A. MiR-122, a paradigm for the role of microRNAs in the liver. J Hepatol 2008;48: 648-656.

22- Hou W, Tian Q, Zheng J, Bonkovsky HL. MicroRNA-196 represses Bach1 protein and hepatitis $\mathrm{C}$ virus gene expression in human hepatoma cells expressing hepatitis C viral proteins. Hepatology 2010;51:1494-1504. 
23- Coulouarn C, Factor VM, Andersen JB, Durkin ME, Thorgeirsson SS. Loss of miR-122 expression in liver cancer correlates with suppression of the hepatic phenotype and gain of metastatic properties. Oncogene 2009;28: 35263536.

24- Krützfeldt J, Rajewsky N, Braich R, Rajeev KG, Tuschl T, Manoharan M, et al. Silencing of microRNAs in vivo with "antagomirs". Nature 2005;438: 685689.

25- Esau C, Davis S, Murray SF, Yu XX, Pandey SK, Pear M, et al. MiR-122 regulation of lipid metabolism revealed by in vivo antisense targeting. Cell Metab 2006;3:87-98.

26- Elmén J, Lindow M, Schütz S, Lawrence M, Petri A, Obad S, et al. LNAmediated microRNA silencing in non-human primates. Nature 2008;452: 896-899.

27- Gatfield D, Le Martelot G, Vejnar CE, Gerlach D, Schaad O, Fleury-Olela F, et al. Integration of microRNA miR-122 in hepatic circadian gene expression. Genes Dev 2009;23:1313-1326.

28- Lanford RE, Hildebrandt-Eriksen ES, Petri A, Persson R, Lindow M, Munk ME, Kauppinen S, Ørum H. Therapeutic silencing of microRNA-122 in primates with chronic hepatitis $\mathrm{C}$ virus infection. Science.2010;327:198-201.

29- Hsu S-H, Wang B, Kota J, Yu J, Costinean $\mathrm{S}$, Kutay $\mathrm{H}$, et al. Essential metabolic, anti-inflammatory, and anti-tumorigenic functions of miR-122 in liver. J Clin Invest 2012;122:2871-2883.

30- Li Y, Gottwein JM, Scheel TK, Jensen TB, Bukh J. 2011. MicroRNA-122 antagonism against hepatitis $\mathrm{C}$ virus genotypes 1-6 and reduced efficacy by host RNA insertion or mutations in the HCV 5= UTR. Proc Natl Acad Sci U S A 108:4991-4996.

http://dx.doi.org/10.1073/pnas.101660610 $\underline{8}$.

31- Janssen HL, Reesink HW, Lawitz EJ, Zeuzem S, Rodriguez-Torres M, Patel K, van der Meer AJ, Patick AK, Chen A, Zhou Y, Persson R, King BD, Kauppinen S, Levin AA, Hodges MR. 2013. Treatment of HCV infection by targeting microRNA. N Engl J Med 368:16851694. http://dx .doi.org/10.1056/NEJMoa1209026.

32- Søren Ottosen, a Todd B. Parsley,b Lu Yang,b Karin Zeh,c Leen-Jan van Doorn, $d$ Eva van der Veer,d Anneke K. Raney,c Michael R. Hodges, and Amy K. Patickc. 2015. In Vitro Antiviral Activity and Preclinical and Clinical Resistance Profile of Miravirsen, a Novel Anti-Hepatitis C Virus Therapeutic Targeting the Human Factor miR-122. Antimicrobial Agents and Chemotherapy, January 2015 Volume 59 Number 1: 599-698.

33- van Rooij E, Kauppinen S. Development of microRNA therapeutics is coming of age. EMBO Mol Med 2014:e201100899. 